\title{
SIMULATED SUBARACHNOID HAEMORRHAGE IN MONKEYS UNDER PENTOBARBITAL-HALOTHANE ANAESTHESIA, WITH PARTICULAR REFERENCE TO MONITORING DURING CEREBRAL ANGIOGRAPHY
}

\author{
J. W. R. MCINTYRE, M.R.C.S., L.R.C.P., F.F.A.R.C.S., \\ D. Dobson, M.B., CH.B., B. K. A. WeIR, M.D., M.SC., F.R.C.S.(C), \\ AND J. D. R. MILLER, M.B., CH.B., F.R.C.P.(C). ${ }^{*}$
}

THE ROUTINE MONITORnG of certain physiological phenomena during anaesthesia is widely practised and has been strongly advocated for neurosurgical patients. ${ }^{1,2}$ Its value lies in demonstrating changes that are a threat to the patient's well-being so that appropriate therapy can be instituted, and in assisting the diagnosis of such alterations in the patient's condition as may occur. There are at least four reported cases $^{3}$ of subarachnoid haemorrhage during a diagnostic neuroradiologic procedure. Three of these occurred when a local anaesthetic technique was employed, and the fourth developed during general anaesthesia with spontaneous ventilation. ${ }^{4}$ It is of interest to consider what changes may be expected during subarachnoid haemorrhage under pentobarbital-halothane anaesthesia with artificial ventilation, and the frequency with which haemorrhage is associated with those changes in the anaesthetized subject. The data reported here were obtained from an investigation of the cerebral angiographic changes associated with a simulated subarachnoid haemorrhage.

\section{Experimental Procedure}

The subjects were female Rhesus monkeys weighing between 2.3 and $6.9 \mathrm{~kg}$. The animals were sedated with sodium pentobarbital administered intraperitoneally $35-75 \mathrm{mg} / \mathrm{kg}$ body weight approximately three hours prior to the subarachnoid injection of blood. In seven experiments this was supplemented by the intravenous injection of $4-10 \mathrm{mg} / \mathrm{kg}$ some sixty minutes prior to injection of blood. Intubation of the trachea with a flexometallic tube was carried out under direct vision. Tubocurarine $0.2 \mathrm{mg} / \mathrm{kg}$ was administered intravenously, and artificial ventilation begun. A Harvard variable volume ventilator and its associated animal ventilation graph (Kleinman and Radford) was used for this purpose. The predicted stroke volume necessary for maintenance of a $\mathrm{PCO}_{2}$ within normal limits was trebled and carbon dioxide was added to the inspired vapour. The gases supplied to the reservoir for the ventilator passed through flowmeters and a Fluotec halothane vaporizer. They consisted of $4 \mathrm{~L} / \mathrm{min}$ of oxygen and approximately $150 \mathrm{cc} / \mathrm{min}$ of carbon dioxide. The Fluotec dial setting was 0.75 ; the inspiration-expiration phase setting was $3: 7$. Once artificial ventilation had begun the system remained unaltered for the duration of the experiment. Thirty minutes

'Departments of Anaesthesia, Neurosurgery, and Radiology, Surgical Medical Research Institute, University of Alberta, Edmonton. Supported in part by Mac grant no. 2835.

Can. Anaes. Soc. J., vol. 16, no. 6, November 1969 
were allowed following the start of artificial ventilation for stabilization prior to the first experimental observations.

\section{MEASUREMENTS}

Cerebrospinal fluid pressure was monitored from a catheter in the subarachnoid space at the level of the third lumbar vertebra. The criterion for satisfactory placement throughout the period prior to the intracranial injection of blood was the association of clearly defined pressure fluctuations with respiration. Systemic arterial pressure was monitored from a catheter in the innominate artery. Statham transducers connected to appropriate Electronics for Medicine preamplifiers and amplifiers were employed. Cardiac rhythm was monitored from lead 2. Permanent records were made on an Electronics for Medicine PR-7 recorder. Oesophageal temperature was measured with a Yellow Springs thermometer. Astrup microtechnique was used to measure blood gases, this being done within an hour of sampling from the innominate artery.

\section{Technique for Simulated Subarachnom Haemorrhage}

A few days prior to the experiment a small skin incision was made in the scalp at a point in the midline $0.5 \mathrm{~cm}$ cephalad to the nasion. A twist drill hole was made at this point. Thus when required a needle about three inches long with a short bevel could be inserted through the skull between the frontal lobes. It was gradually manipulated along the floor of the anterior fossa to a point in the midline about $0.75 \mathrm{~cm}$ anterior to the tuberculum sellae, lying in the subarachnoid space dorsal to the planum sphenoidale. This was done under X-ray control. A lateral view of the needle's final position is shown in Figure 1. At a time when a subarachnoid haemorrhage was to be simulated, $4.0 \mathrm{ml}$ of fresh autogenous blood was injected through the needle over a period of twenty seconds and the needle withdrawn. Subsequent pathological examination determined the exact path taken by the needle.

A few minutes prior to the injection of blood an angiogram was done and the arterial and cerebrospinal fluid pressures as well as the ECG were allowed to stabilize. Thus the injected blood contained a small amount of meglumine iothalamate (Conray 60), pentobarbital, and halothane.

\section{RESULTS}

The results comprise the data obtained from thirty-seven complete experiments. These experiments were classified according to the ECG changes that were associated with the injection of subarachnoid blood. The CSF pressure, measured where necessary as a mean of respiratory or arterial fluctuations; the arterial pressure, presented as the mean of systolic and diastolic pressures; and heart rate changes are shown in Tables I-III. For purposes of tabulation zero time was selected as the point of peak csF pressure. Table I represents those experiments in which a normal cardiac rhythm was unchanged by the injection of blood. The details of experiments in which alterations in the $\mathrm{T}$-wave voltage by more than 25 per cent or T-wave inversion occurred are in Table II. Table III comprises those 


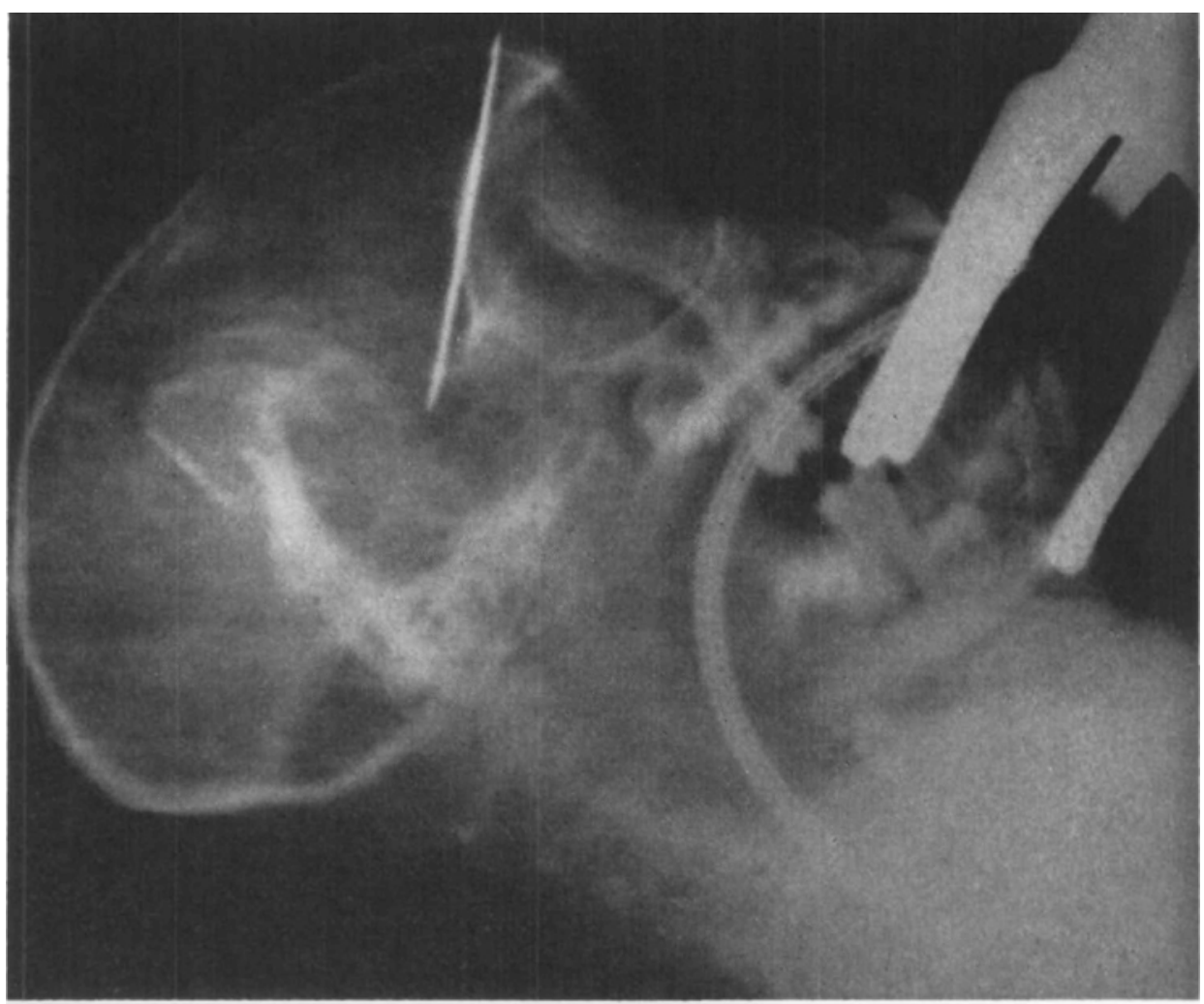

Ficure 1. Lateral view of skull with needle in situ prior to injection of blood.

experiments in which, following simulated haemorrhage, QRs complexes developed that had an abnormal time relationship to the $P$-wave or were derived from varying foci in the $A-V$ node or ventricle in the apparent absence of a P-wave. T-wave changes were also present in some of these instances. In five of the eleven experiments in which QRS changes developed at the time blood was injected, abnormalities, usually an inverted $\mathbf{p}$-wave, already existed. In the remainder, changes first appeared from ten seconds before to sixty seconds after the peak CSF pressure.

The introduction of blood was associated with a rapid increase in CSF pressure, which also diminished rapidly but at a slower rate. Arterial blood pressure changes were not great, nor were changes in cardiac rate, except in some of the instances when alterations in the QRS complex occurred.

The figures in Tables I-III. demonstrate certain trends. However, the values are not statistically significant at each ten-second interval. The $p$ values for a comparison between the abnormal QRs group and the group with an unchanged ECG are shown in Table IV. It appears that in the QRS arrhythmic group the initial intracranial pressure was higher, and a higher blood pressure existed during and following the peak CSF pressure. The cardiac rate was more rapid at this time, usually in association with the arrhythmias. In Table $\mathrm{V}$ are shown the $p$ values for a comparison between all the experiments in which T-wave changes, with or 


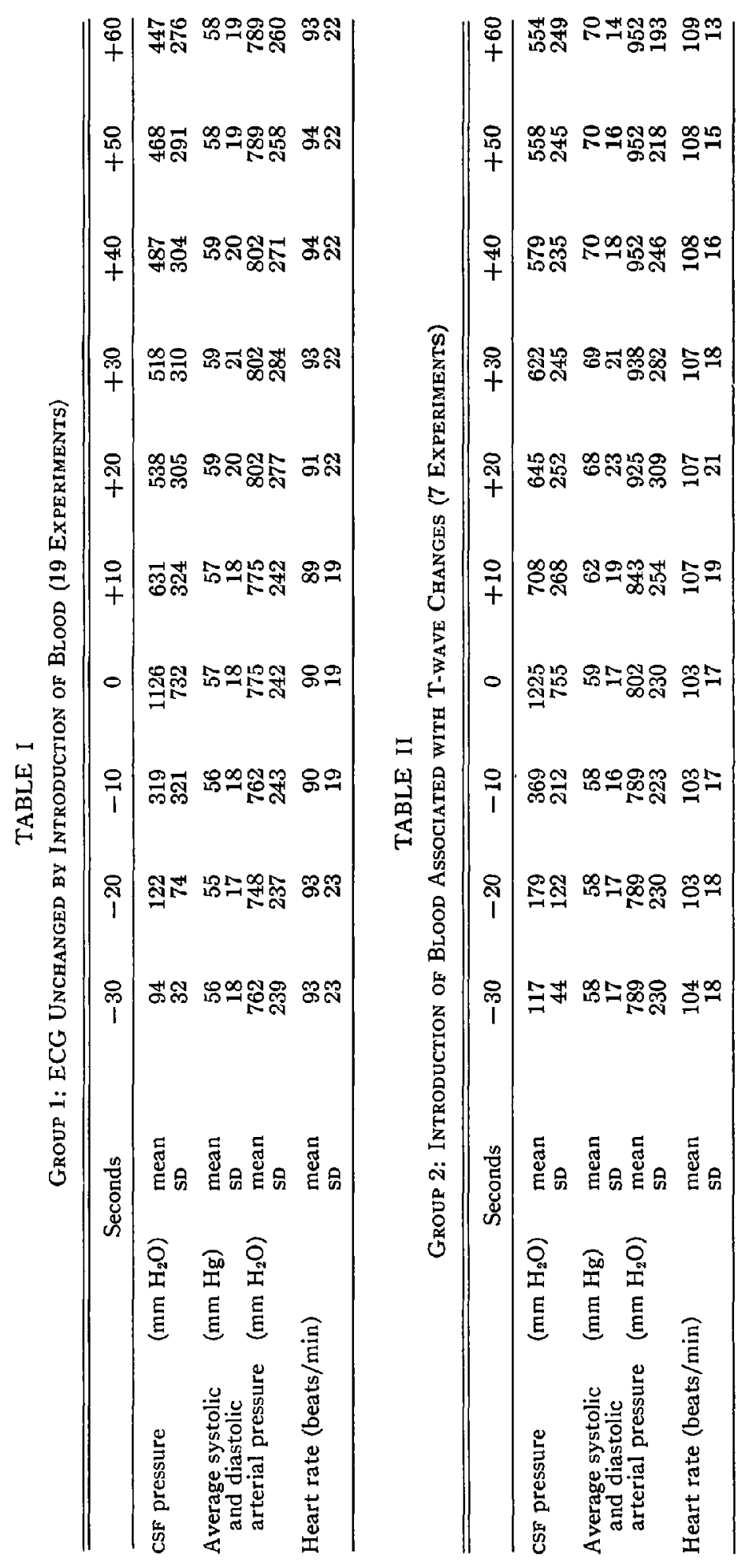




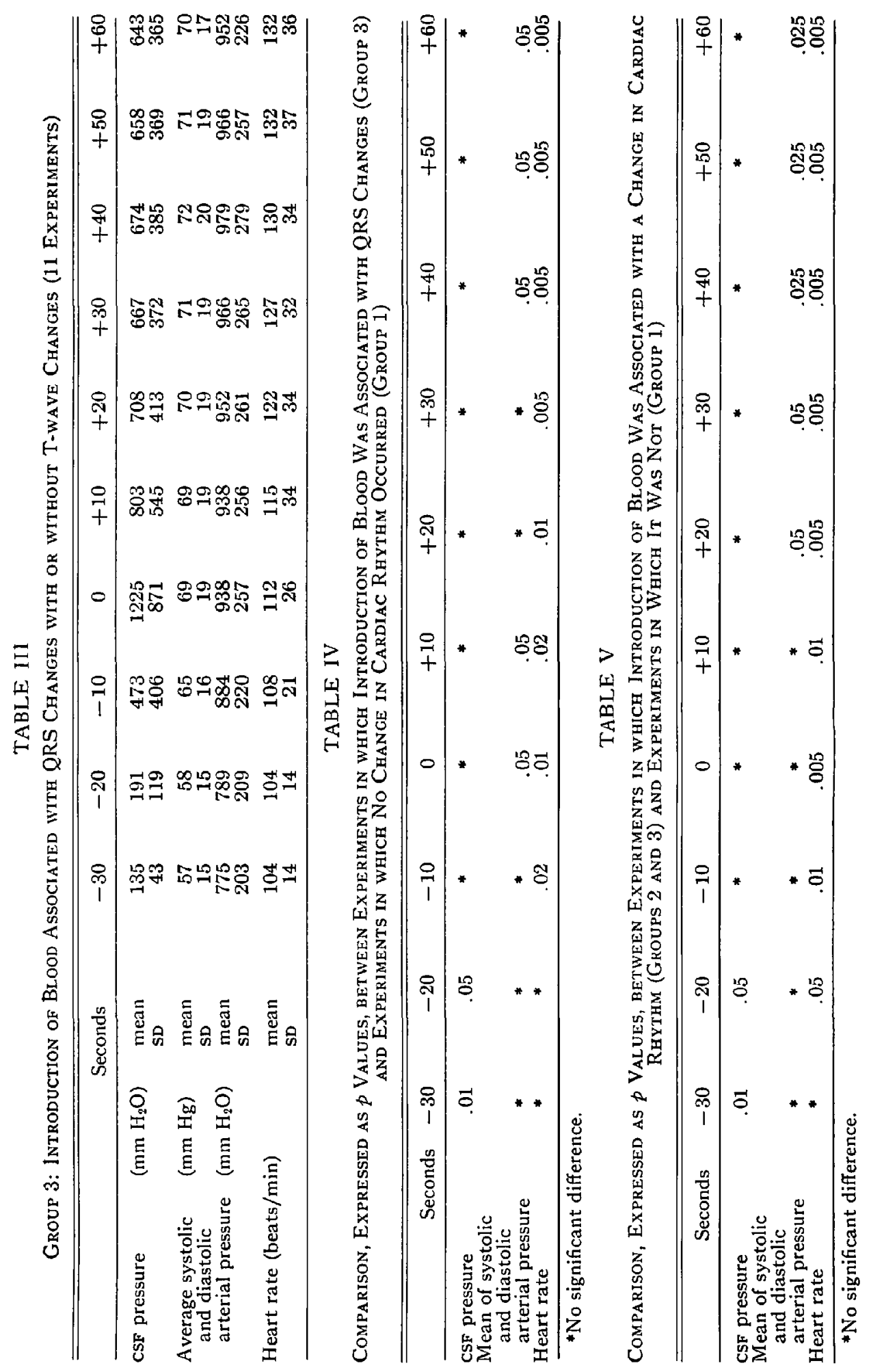


MCINTYRE et al:: SIMULATED SUBARACHNOID HAEMORRHAGE

TABLE VI

\begin{tabular}{llccc}
\hline \hline & & $\begin{array}{c}\text { ECG } \\
\text { unchanged } \\
\text { (group 1) }\end{array}$ & $\begin{array}{c}\text { T-wave } \\
\text { changes } \\
\text { (group 2) }\end{array}$ & $\begin{array}{c}\text { QRs } \\
\text { changes } \\
\text { (group 3) }\end{array}$ \\
\hline Temperature $\left({ }^{\circ} \mathrm{C}\right)$ & mean & 32.4 & 33.0 & 33.1 \\
& SD & 1.97 & 1.20 & 1.30 \\
$\mathrm{pH}$ & mean & 7.32 & 7.37 & 7.33 \\
& sD & 0.06 & 0.10 & 0.07 \\
$\mathrm{PCO}_{2}(\mathrm{~mm} \mathrm{Hg})$ & mean & 46.1 & 44.8 & 49.8 \\
& sD & 7.6 & 10.5 & 5.4 \\
$\mathrm{HCO}_{3}(\mathrm{mEq} / \mathrm{L})$ & mean & 22.8 & 24.7 & 22.9 \\
& sD & 2.60 & 3.76 & 2.8 \\
$\mathrm{Base} \mathrm{excess}_{\text {or deficit }(\mathrm{mEq} / \mathrm{L})}$ & mean & -2.35 & +0.22 & -2.02 \\
& sD & $\mathbf{3 . 5 7}$ & 4.6 & 3.7 \\
\hline
\end{tabular}

without QRS abnormalities, developed (groups 2 and 3), and those in which the ECG remained unchanged (group 1). The statistical findings are similar to those just mentioned.

Details of the temperature and acid base status of the animals at the time the blood was injected are shown in Table VI. The majority were in a state of moderate hypothermia. Blood gas measurements indicated that oxygenation was well maintained at all times, and the $\mathrm{PCO}_{2}$ was occasionally above or below normal limits. Metabolic acidosis was common in all groups. Comparison of the abnormal QRS group, or the combined abnormal QRS and T groups (groups 2 and 3), and the unchanged ECG group (group 1), revealed no significant differences in temperature, $\mathrm{pH}$, or $\mathrm{PCO}_{2}$. The group with an unchanged ECG had a slightly lower standard bicarbonate $(p=0.05)$, and a higher base deficit $(p=0.05)$.

Information regarding subsequent changes in the parameters mentioned is derived from a small number of individual experiments in the various groups because appropriate data is not available from all the experiments. Any tachycardia that occurred diminished during the succeeding three minutes. The T-wave changes persisted, but the severity of other induced arrhythmias diminished. Arterial pressures remained little changed, but the CSF pressures remained increased and after thirty minutes values were recorded in some instances up to double the basal value for the animal.

\section{Discussion}

The signs of the presence of blood in the region of the anterior portion of the Circle of Willis could be due to mechanical stimulation of local structures, to the effects of pressure transmitted from their vicinity, and to biochemical effects of constituents of the blood itself. Of these signs, the electrocardiographic changes have been a subject of study for many years not only because of their intrinsic interest but because of the influence they may exert on the decision to embark on surgical treatment. In a clinical study and review of the literature Wilkins et al. ${ }^{5}$ concluded that the changes consisted mainly of T-wave distortion, $U$-waves or TU fusion waves, QT prolongation, and elevated ST segments. No theoretical reasons 
for the arrhythmias have been confirmed, but postulated mechanisms include increased intracranial pressure, left ventricular subendocardial haemorrhage, coronary atherosclerosis, abnormal electrolytes, or autonomic stimulation associated with brain lesions of the Circle of Willis. Although the opinion that the arrhythmias are of neural origin appears to be widely held it is not universally aocepted, and it has been suggested ${ }^{6-8}$ that the abnormal ECG in patients with brain damage may indicate cardiac dysfunction. Myorcardial damage in association with intracranial haemorrhage has been demonstrated in mice ${ }^{9}$ and in human patients. ${ }^{8}$ Fent $z^{10}$ has carefully drawn attention to the variety of causes of arrhythmia that must be eliminated in any particular case before a causal association between subarachnoid haemorrhage and arrhythmia can be made. However, although the incidence and type of arrhythmias occurring at the time the haemorrhage takes place would be influenced by any existing myocardial pathology, they must be of neural origin, and it is probably the prolonged neurohumoral effects of the haemorrhage that produce more permanent myocardial damage. This could be responsible for persisting or developing cardiac arrhythmias.

The observations in the present study were made at a time much more closely related to the actual haemorrhage than in the cases considered by Wilkins, and it is not surprising that the ECG findings more closely resemble those referred to in a review by Russell, ${ }^{11}$ experimental observations by Ducker, ${ }^{12}$ and a clinical study of mechanical stimulation during intracranial surgery by Pool et al. ${ }^{13}$ Their reported abnormalities are bradycardia and extrasystoles, low nodal tachycardia, T-wave elevation, ST depression, and absent P-waves. Pool associated manipulation of segments of the Circle of Willis, the dura mater, and the posterior root of the trigeminal nerve with the development of arrhythmias. Bradycardia occurred with retraction of the brain and intracranial manipulation of the $\mathrm{Ix}$ and $\mathrm{x}$ cranial nerves. Simple mechanical irritation of the orbital surface of the frontal lobe and the anterior gyrus cinguli (cortical areas 13 and 24) may also produce arrhythmias. ${ }^{14}$ The transient nature of the tachycardia and many of the arrhythmias in the present study reflects the apparently brief period of maximum stimulation produced by a single haemorrhage. The intracranial pressure increased rapidly but quickly responded to the existing homeostatic mechanisms. The variations in pressure developing in individual experiments was very great and in a few instances the actual increase was small. Mitchell et $a ._{.}{ }^{15}$ have indicated that measurements of cisternal and lumbar pressures do not necessarily represent the true levels when intracranial pressure is raised by a rapidly expanding intracranial mass, and it is possible that in those experiments in which a small increase in pressure was recorded the intracranial pressure was actually higher. In a very few experiments fluid could be observed dripping from the nostrils, ${ }^{15}$ but the number was insufficient to suggest that reflex stimulation from intranasal sites ${ }^{16}$ played a significant role in the origin of the arrhythmias. In the present study it appears that in the experiments exhibiting cardiac arrhythmias associated with the injection of blood, the CSF pressure exceeded the critical arterial or venous pressures for a period of time sufficient to produce a pressor response as evidence of a failing medullary circulation. The arrhythmias themselves may not be directly due to this raised intracranial pressure. The rising blood pressure may have lowered the threshold for arrhythmias induced by other stimuli and the reduced contractility of a myo- 
cardium in the presence of a metabolic acidosis or depressed synaptic transmission in the central nervous system may in part account for the failure of the animals in group 1 to develop arrhythmias. The arrhythmias, the CsF pressure, and systemic arterial pressure findings reported here are in keeping with those that might be anticipated in the light of already published work. However, 19 of the 39 experiments were considered to have an ECG unchanged by the simulated subarachnoid haemorrhage, although it is possible that more sophisticated recording of myocardial electrical activity would have revealed alterations in every instance.

The existence of these cases might possibly be explained by the fact that the demonstrated differences in CSF pressure or systemic arterial pressure are critical for the development of arrhythmias. However, this seems inadequate, and other factors need to be considered. These can be discussed under two headings: the presence of an increased stimulus and a reduced threshold to arrhythmogenic stimuli. Post mortem studies revealed little difference between the two groups, and an error in needle placement could not account for the difference, but the initial intracranial pressure in one group might cause a wider distribution of blood with a consequent increased stimulus and greater likelihood of arrhythmias. Other factors that cannot be completely excluded are a distribution of blood in the arrhythmic groups that produced an acute dynamic axial distortion of the pontomedullary portion of the brain stem, ${ }^{17}$ and kinking of the vertebral basilar arterial system. ${ }^{18}$ Profound cardiorespiratory changes without gross changes in CSF pressure can be produced.

The threshold to stimulus of the various tissues involved in the production of arrhythmias is influenced by factors such as temperature, acid-base balance, blood and tissue gases, electrolytes, and drugs present. It is noteworthy that of the eleven subjects in which QRS arrhythmias developed, four had an inverted $P$ or abnormal QRs prior to the injection of blood. These could have been due to the factors mentioned or the presence of the needle through which the blood was introduced. Its introduction was rarely associated with alterations of any of the parameters mentioned, but in two of these cases $A-V$ nodal beats occurred. The effect of certain drugs used in anaesthesia on centrally induced cardiac arrhythmias has been described by Purpura. ${ }^{19}$ It was found that among the drugs tested barbiturates had a depressant effect. In the experiments reported here the barbiturate dosage varied considerably and it is likely that distribution and metabolism of the drug also varied. Thus adequate central depression with pentobarbital may have played a part in preventing the development of arrhythmias in some cases. It is likely that concentrations of halothane in the body were more comparable between animals than those of pentobarbital.

Experimental evidence has recently demonstrated ${ }^{12}$ the elevated pulmonary arterial and venous pressures that could precipitate the pulmonary oedema sometimes associated clinically with intracranial haemorrhage. ${ }^{11}$ There was no evidence in the experiments reported here that suggested the development of pulmonary oedema or gross changes in pulmonary compliance.

In conclusion, the experiments reported here deal with a very brief period at the time subarachnoid haemorrhage occurs. They differ from many clinical situations in that there are temperature, acid-base status, and species differences. Furthermore, no allowance is made for the artificial conditions that might preci- 
pitate the haemorrhage or the immediate changes associated with the actual rupture of a blood vessel. However, it is felt that, bearing in mind the factors involved, the results have clinical application. It appears that monitoring of CSF pressure at the time a subarachnoid haemorrhage occurs in a pentobarbital-halothane anaesthetized monkey provides evidence of the haemorrhage, but this increase in pressure is of varying amount and the gross changes are transient. Systematic arterial pressure changed at the time of the haemorrhage but the alterations were small and might only be measured reliably by intra-arterial methods. The numerous reasons for CSF and arterial pressure fluctuations in the anaesthetized subject have been widely documented, and if these changes are considered indicative of subarachnoid haemorrhage under anaesthesia, other causes must be excluded and confirmatory evidence from other parameters obtained. The sudden development of T-wave or ST changes, nodal rhythm, or tachycardia from foci of impulse formation in the A-v node or ventricle can be accepted in the absence of other causes as evidence that subarachnoid haemorrhage has suddenly occurred, though the absence of ECG changes apparently cannot permit the assumption that haemorrhage has not occurred. The monitoring of the parameters employed in this study provides valuable data that are relevant to the patient's safety. Under the conditions of anaesthesia described they are insufficient for a definite diagnosis of subarachnoid haemorrhage under anaesthesia to be made whenever it occurs.

\section{SUMMARY}

There are at least four reported cases of subarachnoid haemorrhage taking place during a neuroradiologic procedure. It is of interest to consider what changes may be expected during subarachnoid haemorrhage under pentobarbitalhalothane anaesthesia with artificial ventilation. Experiments were performed on female Rhesus monkeys at varying temperatures and acid-base status. Parameters observed were lead 2 ECG, systemic arterial blood pressure, and CSF pressure. Subarachnoid haemorrhage was simulated by injecting fresh autogenous blood through a needle the point of which was placed in a position in the midline about $0.75 \mathrm{~cm}$ anterior to the tuberculum sellae, dorsal to the planum sphenoidale. The conclusions reached were that under the conditions of the experiments the monitoring of CSF pressure at the time of haemorrhage provides evidence of haemorrhage, but that this increase in pressure is of varying amount, and transient. Systemic arterial pressure changes are small. The sudden development of T-wave or st changes, nodal rhythm, or tachycardia from foci of impulse formation in the A-v node or ventricle in the absence of other causes can be accepted as evidence that subarachnoid haemorrhage has occurred, though the absence of obvious ECG changes apparently cannot permit the assumption that a haemorrhage has not occurred.

\section{RÉSUMÉ}

Il existe au moins quatre cas de rapportés d'hémorragie subarachnoïdienne survenue au cours d'une manœuvre neuroradiologique. Il est intéressant de passer en revue les changements qui peuvent survenir durant une hémorrhagie subarach- 
noïdienne durant une anesthésie au pentobarbital et halothane et ventilation artificielle. Nous avons fait des expériences sur des guenons Rhesus à des températures et à des équilibres acide-base différents. Les paramètres surveillés ont été: l'ECG, deuxième dérivation, la pression artérielle systémique et la pression du liquide céphalo-rachidien (CSF). Nous avons simulé l'hémorragie subarachnoïdienne en injectant du sang frais autogène avec une aiguille dont la pointe était placée à un endroit sur la ligne médiane à environ $0.75 \mathrm{~cm}$ antérieur au "tuberculum sellae," dorsal au "planum sphénoïdale." Les conclusions sont les suivantes: dans les conditions de l'expérience, la lecture de la pression du LCR (CSF) au moment de l'hémorragie procure l'évidence de l'hémorragie; toutefois, l'augmentation de pression est variable et transitoire. Les changements de la pression systémique sont réduits. L'apparition soudaine d'une onde $\mathbf{T}$ ou de modifications ST, d'un rythme nodal ou de tachycardie venant de foyers d'influx du nœud A-v ou du ventricule en l'absence d'autres causes peut être acceptée comme évidence qu'une hémorragie subarachnoïdienne est survenue bien que l'absence de signes électrocardiographiques évidents ne peut pas permettre, selon toute apparence, d'affirmer qu'une hémorragie n'a pas eu lieu.

\section{REFERENCES}

1. Michenfelder, John D.; Gronert, Geradd A.; \& Refder, Kat. Neuroanesthesia. Anesthesiology. 30: 65 (1969).

2. Gilbert, R. G. B.; Brindle, G. Fred; \& Galindo, Anibal. Anesthesia for Neurosurgery. Int. Anesth. Clin. 4: 4 (1966).

3. Murphy, Daniel J. \& Goldberg, Robert J. Extravasation from an Intracranial Aneurysm during Carotid Angiography: Case Report. J. Neurosurg. 27: 459 (1967).

4. Jenkinson, E. L.; Sugar, O.; \& Love, H. Rupture of an Aneurysm of the Internal Carotid Artery during Cerebral Angiography. Am. J. Roent. 71: 958 (1954).

5. Wilkms, Robert H.; Alexander, James; \& Odom, Guy L. Intracranial Arterial Spasm: A Clinical Analysis. J. Neurosurg. 29: 121 (1968).

6. Koskelo, P.; Punsar, S.; Sipala, W. Subendocardial Haemorrhage and ECG Changes in Intracranial Bleeding. Brit. Med. J. 1: 1479 (1964).

7. Hoffbrand, B. I. \& MoRgan, B. D. D. Functional Significance of Electrocardiographic Changes Associated with Subarachnoid Haemorrhage. Lancet. 1: 844 (1965).

8. Connor, Richard C. Heart Damage Associated with Intracranial Lesions. Brit. Med. J. 3: 29 (1968).

9. Burch, G. E.; Sun, S. C.; Colcolough, H. L.; Depasouale, N. P.; \& Sohal, R. S. Acute Myocardial Lesions Following Experimentally Induced Intracranial Haemorrhage in Mice: A Histological and Histochemical Study. Arch. Path. (Chicago). 84: 517 (I967).

10. Fentz, V. \& Gormsen, J. Electrocardiographic Patterns in Patients with Cerebrovascular Accidents. Circulation. 25: 22 (1962).

11. Russelt, A. A. The Association of Subarachnoid Haemorrhage with an Abnormal Electrocardiogram and Acute Pulmonary Oedema. Guys Hosp. Rep. 115: 463 (1966).

12. Ducker, Thomas D. \& Simmons, Richard L. Increased Intracranial Pressure and Pulmonary Edema: Part 2, The Hemodynamic Response of Dogs and Monkeys to Increased Intracranial Pressure. J. Neurosurg. 28: 118 (1968).

13. Pool, J. Lamrence. Vasocardiac Effects of the Circle of Willis. Arch. Neurol. \& Psych. 78: 355 (1957).

14. Hoff, Ebhe Cuntis; Kell, Joseph F. Jn.; \& Carrolx, Marcus N. Effects of Cortical Stimulation and Lesions on Cardiovascular Functions. Physiol. Rev. 43: 68 (1963).

15. Mitchelt, O. C.; Deta Torre, E.; Alexander, E.; \& Davis, D. H. The Non-filling Phenomenon during Angiography in Acute Intracranial Hypertensions: Report of 5 Cases and Experimental Study. J. Neurosurg. 18: 766 (1962).

16. Widdicomaz, J. S. Clinical Significance of Reflexes from the Respiratory System: Review Article. Anesthesiology. 23: 434 (1962).

17. Thompson, R. K. \& Malina, S. Dynamic Axial Brain Stem Distortion as a Mechanism 
Explaining the Cardio-respiratory Changes in Increased Intracranial Pressure. J. Neurosurg. 16: 664 (1959).

18. Jornson, R. T. \& YATEs, P. O. Brain Stem Haemorrhages in Expanding Supratentorial Conditions. Acta Radiol. Stockh. 46: 250 (1956).

19. Purpura, Domtnick P.; Pool, J. Lawrence; Housepian, Edgar M.; Girado, Martin; JaCOBSEN, Sherwood A.; \& SEYmour, R. James. Hypothermic Potentiation of Centrally Induced Cardiac Irregularities. Anesthesiology. 19: 27 (1958). 